\title{
The Scientific Operations of Snow Eagle 601 in Antarctica in the Past Five Austral Seasons
}

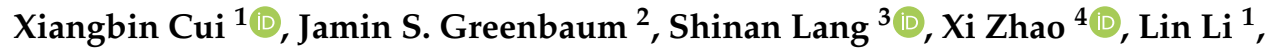 \\ Jingxue Guo ${ }^{1, *}$ and Bo Sun ${ }^{1}$ \\ 1 Polar Research Institute of China, Shanghai 200136, China; cuixiangbin@pric.org.cn (X.C.); \\ lilin@pric.org.cn (L.L.); sunbo@pric.org.cn (B.S.) \\ 2 Institute for Geophysics, University of Texas at Austin, Austin, TX 78758, USA; jamin@utexas.edu \\ 3 Faculty of Information Technology, Beijing University of Technology, Beijing 100124, China; \\ langshinan@bjut.edu.cn \\ 4 Chinese Antarctic Center of Surveying and Mapping, Wuhan University, Wuhan 430072, China; \\ xi.zhao@whu.edu.cn \\ * Correspondence: guojingxue@pric.org.cn
}

Received: 3 August 2020; Accepted: 13 September 2020; Published: 15 September 2020

\begin{abstract}
The Antarctic ice sheet and the continent both play critical roles in global sea level rise and climate change but they remain poorly understood because data collection is greatly limited by the remote location and hostile conditions there. Airborne platforms have been extensively used in Antarctica due to their capabilities and flexibility and have contributed a great deal of knowledge to both the ice sheet and the continent. The Snow Eagle 601 fixed-wing airborne platform has been deployed by China for Antarctic expeditions since 2015. Scientific instruments on the airplane include an ice-penetrating radar, a gravimeter, a magnetometer, a laser altimeter, a camera and a Global Navigation Satellite System (GNSS). In the past five austral seasons, the airborne platform has been used to survey Princess Elizabeth Land, the largest data gap in Antarctica, as well as other critical areas. This paper reviews the scientific operations of Snow Eagle 601 including airborne and ground-based scientific instrumentation, aviation logistics, field data acquisition and processing and data quality control. We summarize the progress of airborne surveys to date, focusing on scientific motivations, data coverage and national and international collaborations. Finally, we discuss potential regions for applications of the airborne platform in Antarctica and developments of the airborne scientific system for future work.
\end{abstract}

Keywords: Snow Eagle 601; aerogeophysics; Princess Elizabeth Land; ice-penetrating radar; Antarctic ice sheet

\section{Introduction}

Antarctica is the most hostile and remote continent on Earth, possessing a large area of over 14 million $\mathrm{km}^{2}$. Overall, $98 \%$ of the continent is covered by flowing ice sheets, causing many areas to be inaccessible from the ground [1]. The Antarctic continent and overlying ice sheet both play crucial roles in the recent sea level rise in response to global warming [1]. Crucial questions include how is Antarctica changing on regional and continental scales, what drives and controls Antarctica's changes and what is Antarctica's impact on climate and sea level changes. To answer the questions proposed by the Scientific Commission on Antarctic Research (SCAR), Antarctic and Southern Ocean Science Horizon Scan and the Antarctic Roadmap Challenges (ARC) Project [2,3], observations in Antarctica with high accuracy, resolution and reliability are urgently needed in order to improve our understanding of the continent and ice sheets and predict their changes and influences through numerical modeling. 
Airborne surveys have been used to study Antarctica since the 1960s [4,5]. Multidisciplinary instruments onboard airborne platforms provide an efficient and flexible means of data collection over Antarctica, satisfying various requirements for polar exploration [6]. As a bridge between ground-based and space-borne observation, airborne surveys can acquire data with high efficiency in areas that are hard to access from the ground and achieve more accurate and higher resolution measurements relative to satellite remote sensing. Crucially, we cannot yet collect ice-penetrating radar (IPR) data from orbital platforms due primarily to interference from the ionosphere. With these advantages, airborne surveys have been continuously and extensively used in Antarctica for the past several decades. A number of large international airborne campaigns have been launched to survey Antarctica including the early SPRI-NSF-TUD (Scott Polar Research Institute, the National Science Foundation and the Technical University of Denmark) survey [7], AGAP (Antarctica's Gamburtsev Province [8]), IMAFI (Institute-Moller Antarctic Funding Initiative [9]), PolarGap [10], ICECAP (International Collaborative Exploration of the Cryosphere by Airborne Profiling [11-13]) and OIB (Operation IceBridge, https://www.nasa.gov/mission_pages/icebridge/index.html) surveys, as well as airborne surveys by German Polar 5 and Polar 6 in Dronning Maud Land and Dome F, respectively e.g., [14]. These projects have mainly focused on measuring the geometry and properties of ice sheets, subglacial topography and the geological structure of the continent. Based on airborne survey data, three important datasets, Bedmap (Antarctic Bedrock Mapping [15]), ADMAP (Antarctic Digital Magnetic Anomaly Project [16]) and AntGG (Gravity and Geoid in Antarctica [17]), have been compiled and gradually updated through international efforts. These datasets provide primary knowledge of ice thickness, bedrock topography and the geological settings of Antarctica.

China has recently become involved in Antarctic aviation. In 2015, a BT-67 airplane called Snow Eagle 601 was deployed to operate in Antarctica for Chinese National Antarctic Research Expeditions (CHINAREs [13]). An airborne IPR, a gravimeter, a magnetometer, a laser altimeter, a camera and a GNSS were configured and integrated on the airplane, offering powerful capabilities for aerogeophysical investigations. Meanwhile, as a branch of ICECAP, an international campaign of ICECAP/PEL was initiated by China to survey Princess Elizabeth Land (PEL), the largest data gap in Antarctica, using the Snow Eagle 601 airborne platform along with collaboration with the USA and the UK. In the past five austral seasons, the airborne platform has been continuously applied to survey PEL and other critical areas in East Antarctica including the Amery Ice Shelf, Ridge B, the West Ice Shelf, the Shackleton Ice Shelf and the George V Coast.

This paper reviews the scientific designs and operations of Snow Eagle 601 in Antarctica from the past five austral seasons from 2015 to 2020. First, we introduce the Snow Eagle 601 platform and ground-based scientific equipment. Next, we describe scientific operations supporting the aerogeophysical surveys including aviation support, survey design and data collection and processing. Finally, we summarize the progression of the airborne survey and discuss potential developments for airborne instruments and possible regions for additional survey in Antarctica for future years.

\section{Snow Eagle 601 Airborne Surveying System}

\subsection{Airborne Platform}

The Snow Eagle 601 airplane is a modified DC-3 aircraft, now known as a DC-3T or, more formally, a BT-67. Standard improvements include new Pratt \& Whitney (East Hartford, CT, USA) turbine engines, a modern avionics system, fuel system and structural reinforcements among others. Modifications of the aircraft for polar operations include combined ski/wheel landing gear, an oxygen system, an air conditioner and a large cargo door. Ice-penetrating radar (IPR) antennas are mounted beneath the wings, a tail boom is used for a magnetometer and rolling doors beneath the fuselage are opened in flight to support a laser altimeter and a visual camera. GNSS antennas are mounted on each wing over the center of gravity (CG) and forward of the CG. Structural enhancements, electrical 
conduit and junction boxes to support power and data connections to science instruments are also installed on Snow Eagle 601.

Currently, the scientific instruments on the aircraft emphasize aerogeophysical investigations including an IPR made to be functionally similar to the High Capability Airborne Radar System (HiCARS) developed by the University of Texas Institute for Geophysics (UTIG) [13,18] for deep ice-penetrating capability, a GT-2A gravimeter [12], a CS-3 magnetometer, a Riegl LD90-3800-HiP laser altimeter, an Elphel NC353L downward-looking camera and a JAVAD dual frequency, four channel, carrier-phase GNSS receiver (Figure 1 and Table 1). Redundant interfaces were also reserved for the installation of more instruments in the future. More detailed descriptions of Snow Eagle 601 and the airborne scientific systems can be found in Cui et al. [13].
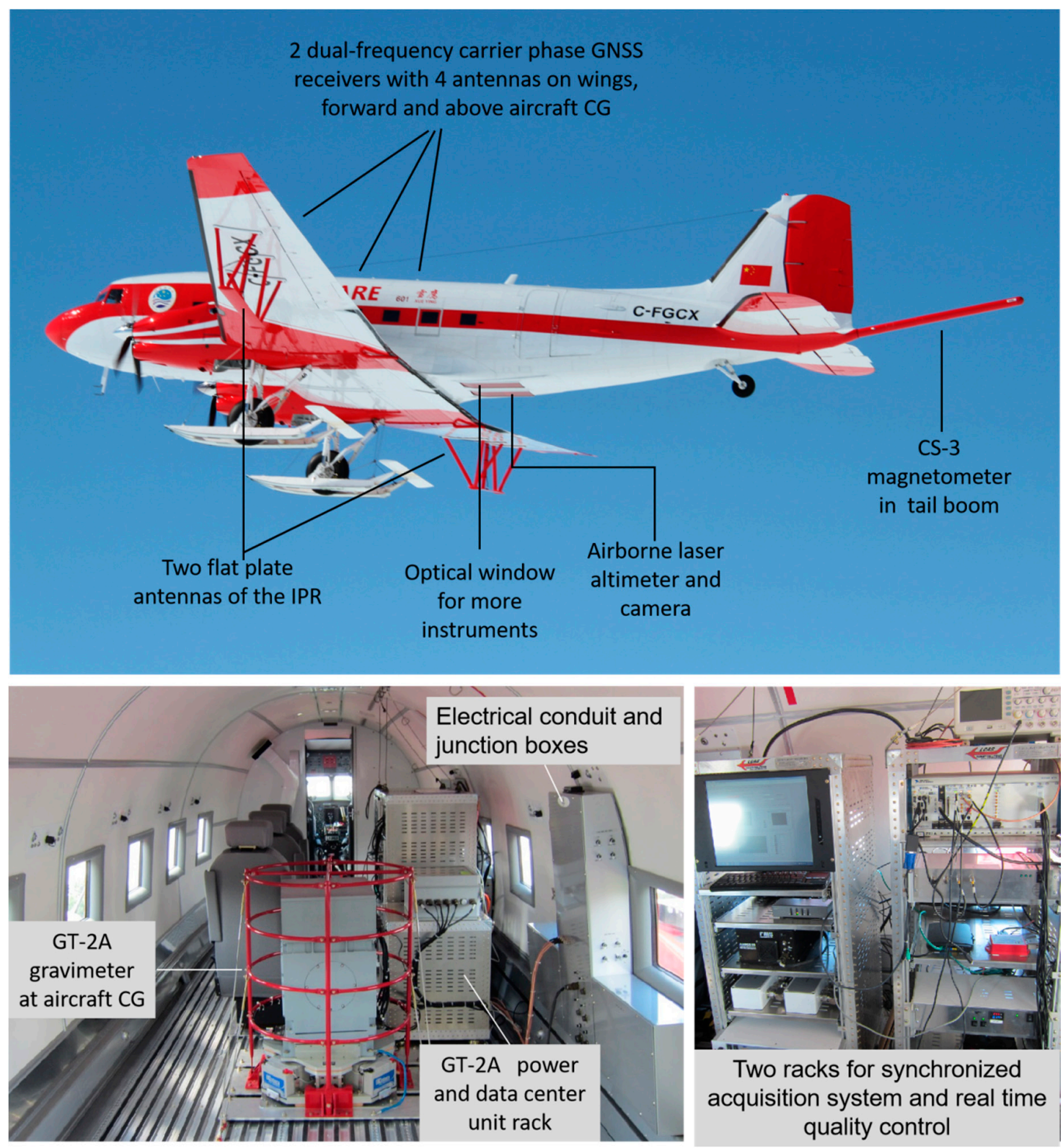

Figure 1. The Snow Eagle 601 platform and instruments. 
Table 1. The Snow Eagle 601 airborne instruments and their typical performance and observing targets.

\begin{tabular}{|c|c|c|}
\hline Airborne Instruments & Performance & Targets \\
\hline $\begin{array}{l}\text { Ice-penetrating radar } \\
\text { (IPR) }\end{array}$ & $\begin{array}{l}\text { Deep penetrating ability: }>4000 \mathrm{~m} \text {; depth } \\
\text { resolution: } 5.6 \mathrm{~m} \text { in ice; coherent system; } \\
\text { both low gain and high gain channels; } \\
500-1500 \mathrm{~m} \text { nominal surface range }\end{array}$ & $\begin{array}{l}\text { Map ice sheet geometry and } \\
\text { subglacial topography; interpret } \\
\text { subglacial conditions }\end{array}$ \\
\hline GT-2A gravimeter & $\begin{array}{l}\text { Improved performance over other } \\
\text { conventional gravimeters: dynamic range } \\
\text { (>1000 Gal) and sensitivity (resolution: } \\
0.02 \mathrm{mGal}) \text {; can be used in turbulence; } \\
\text { functions well on draped surveys }\end{array}$ & $\begin{array}{l}\text { Measure gravity anomalies; infer } \\
\text { deep geological and tectonic } \\
\text { structures, subglacial water and } \\
\text { sediment depth; bathymetry } \\
\text { under ice shelves [12] }\end{array}$ \\
\hline CS-3 magnetometer & $\begin{array}{c}\text { High sensitivity (resolution: } 0.00032 \mathrm{nT} \text { ) } \\
\text { and very low noise (system noise: } \\
<0.0001 \mathrm{nT} \text { ) }\end{array}$ & $\begin{array}{l}\text { Measure magnetic anomalies; infer } \\
\text { lithology, deep geological and } \\
\text { tectonic structures }\end{array}$ \\
\hline Laser altimeter & Maximum range: $1500 \mathrm{~m}$; accuracy: $15 \mathrm{~cm}$ & $\begin{array}{l}\text { Measure accurate flight height } \\
\text { over the snow or ice surface }\end{array}$ \\
\hline Camera & - & Characterize surface features \\
\hline $\begin{array}{c}\text { Global Navigation } \\
\text { Satellite System (GNSS) }\end{array}$ & $\begin{array}{l}\text { Dual frequency, four-channel } \\
\text { carrier-phase GNSS receiver }\end{array}$ & $\begin{array}{c}\text { Provides aircraft position } \\
\text { and attitude }\end{array}$ \\
\hline
\end{tabular}

Two to four days were needed to install the instrument suite onto the aircraft including two days for the gravimeter warm-up and auto-calibration before flights began. Ground testing of the instrument suite was required to confirm functionality before the first flight test. Normally, a short ( 3-4 h) flight test would be conducted to test the operation of the suite, emphasize the high power radar amplifier and to calibrate the magnetometer. At the end of a season, airborne instruments can be de-configured from the airplane in one day.

\subsection{Base Stations}

As shown in Figure 2, two GPS base stations and a magnetic base station were installed beside the landing area to enable the differential processing of airborne GNSS data and to record variations in the magnetic field due to solar activity. GNSS and magnetic data from observatories in Zhongshan Station were also recorded during each flight as a backup for the instruments running at the skiway. When flights were conducted at other Antarctic stations, available GNSS and magnetic data from the nearest base station was requested for potential use. Gravity ties between the aircraft parking area and absolute gravity stations were measured at least twice during each season for airborne gravity data processing.

\section{Aviation Support}

\subsection{Aviation Groups}

Snow Eagle 601 is owned and managed by the Polar Research Institute of China (PRIC, Shanghai, China) but the airplane is registered in Canada; aviation operation and maintenance services are provided by Calgary, Alberta-based Kenn Borek Air Ltd. (KBA, Calgary, AB, Canada). KBA is a commercial company with a long history of complex polar aviation operations; only a three-person KBA crew is required for all aviation operations of the aircraft.

The PRIC determines annual missions and establishes the schedule for both the scientific and logistical operations of Snow Eagle 601. A field team from the PRIC and collaborative institutes is organized to support flight missions and carry out airborne surveys with separate scientific and logistical groups, each typically composed of six members. The scientific group is split into two sub-groups with three people managing flight operations (FOP) and the other three managing base operations (BOP). The main duty of FOP is to install and maintain airborne instruments, design flight 
plans and acquire data on each flight. The main duty of BOP is to conduct data processing and quality control (QC), operate and maintain base stations and prepare media and flight documents for FOP.

In a typical mission cycle, BOP initiates magnetic and GPS base station recording while FOP starts a pre-flight reference measurement on the aircraft gravimeter and starts recording GPS on the aircraft receivers at least half an hour before the aircraft moves. During the airborne survey (about seven hours), FOP will manage and monitor data acquisition on the airplane while BOP monitors the base instruments. Generally, only two of the three FOP members will fly on a given flight as each additional operator reduces survey flying time by about 15 to $30 \mathrm{~min}$ (80-160 $\mathrm{km}$ range) because the fuel load is limited by the aircraft weight. After landing, FOP and BOP require about an hour to complete a post-flight gravity reference measurement and recover all media including GPS data that are left to record for $30 \mathrm{~min}$ after landing. BOP collects media from the magnetometer and GPS base stations. After the post-flight data collection, both airborne data and base station data are moved to the BOP office. BOP requires about five hours to carry out data download, processing, quality control (QC), document printing and scanning and archiving. BOP and FOP discuss data QC results together to confirm that all instruments performed nominally and the collected data are of the desired quality before confirming the next flight.

\subsection{Logistical Support}

The scientific operations of Snow Eagle 601 mainly rely on logistical support from the Chinese Zhongshan Station and the Russian Progress Station Skiway located in the Larsemann Hills along Ingrid Christensen Coast, East Antarctica. The distance between the skiway and Zhongshan Station is about $10 \mathrm{~km}$. The skiway is maintained by Progress Station during the aviation operations of Snow Eagle 601 based on collaboration between Russia and China. A temporary camp is built beside the skiway during aviation operations of each year (Figure 2). Custom-designed cabins and containers with different functions are configured for accommodation and living, power supply, field data processing and the storage of aviation accessories and scientific instruments (Figure 2). Ground support vehicles including Arctic Trucks, PistenBully snow vehicles and snowmobiles are used to transport personnel and equipment between Zhongshan and the Progress Skiway, maintain the camp and support field work.

Daily weather forecasts are provided by Zhongshan Station, Progress Station and Davis Station; the Antarctic Mesoscale Prediction System (AMPS, https://www2.mmr.ucar.edu/rt/amps) is additionally monitored regularly by the flight crew. The crew will choose from multiple flight plans based on all available weather reports.

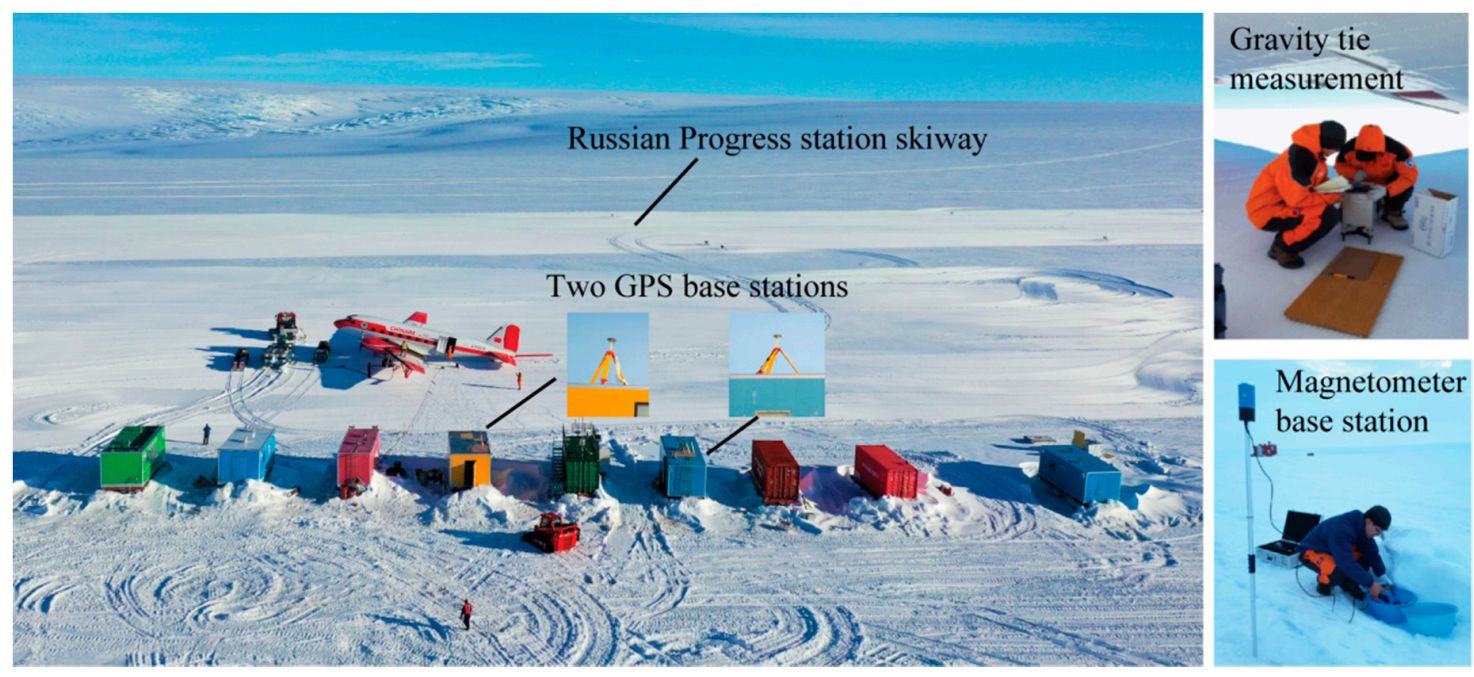

Figure 2. Field camp for aviation and scientific operations of Snow Eagle 601 located along the Russian Progress Station Skiway. 


\section{Airborne Survey and Data Processing}

\subsection{Flight Plan Design}

Flight plans are designed based on pre-season experiment designs that consider the scientific significance of each line in the context of previously completed surveying and flight limitations (e.g., maximum range and weather conditions) in target areas. Before a flight mission, two or three potential flight plans are prepared for the pilots to choose according to weather conditions. Key waypoints along a flight route are provided in the flight plans as well as surface elevation, flight range and flight altitude at each waypoint. As flight plans are created using projected coordinates but the aircraft is flown using geographic coordinates, the distance between each waypoint is kept to less than $50 \mathrm{~km}$ to minimize the resulting track error.

A target area can rarely be comprehensively surveyed on one flight. Systematic flight planning and survey organization allows an airborne survey to return to the target area and fill in coverage systematically and is robust against weather and equipment failures. This approach also allows elegance in analysis. We use a system of data organization developed by the University of Texas Institute for Geophysics that maps our survey plans and survey metadata into the organization of the collected data. The organizing elements are termed PSTs (project/set/transect). The project is generally defined according to the name of surveyed area or scientific campaign (e.g., PEL, representing Princess Elizabeth Land). The set indicates the survey platform used and the version of the instrument suite. For Snow Eagle 601, the first three letters in the set are taken from the final three letters of the aircraft tail number (C-FGCX); the last two numbers identify the version of the instrument suite used (e.g., GCX0g, representing the seventh version of the first acquisition system on C-FGCX). The transect represents particular survey lines within a survey area defined by the project, with orientations planned based on the target areas. Transects are typically either planned as radial lines for maximum range or as grids of perpendicular lines over an area of interest. For the latter, $X$ lines are typically planned to run along the glacier flow and perpendicular $Y$ lines are planned to run across the ice flow. $X$ and $Y$ lines are numbered sequentially from one to a number high enough to cover the survey area with a chosen line spacing; the final digit in each transect is used to denote whether the flown line is new (with an ' $a$ ' designation) and the final digit will be incremented from a to $\mathrm{z}$ for each repeated line or extension to the line flown on subsequent flights. PSTs divide a continuous flight into different transects by turning points and are unique transects of data collected at a discrete location and at a particular time. PSTs are imported into a data acquisition system by FOP during the flight and they are very useful for future data processing, organization and interpretation. Therefore, PSTs are clearly noted in a flight plan. The original definition of PST nomenclature can be found in UTIG's technical report database [18].

Chosen experiment designs depend on the given scientific objectives. While a radial survey plan is the most efficient way to explore large unknown areas, it also has few crossovers useful for evaluating data consistency and results in very long baselines that can result in degraded GNSS solutions. Radial lines were chosen for the first season flown by the Snow Eagle 601 airborne platform to quickly cover all of Princess Elizabeth Land. Gridded survey plans are generally chosen for investigating critical targets with a high spatial resolution requirement or where many crossovers are needed for data validation. Disadvantages to grids include longer transit lines to the survey areas, many turns and heavy logistical support required. For small outlet glaciers and ice streams, a gridded survey is the best choice as it can focus on and cover the target region in detail and also follow glaciological features.

The flight parameters cannot usually be the best for all of the instruments onboard so compromises must be made in the flight plans, often depending on the prior goals of the airborne survey. The airborne IPR should be flown at a constant height of over 500 meters above the surface to avoid saturating the low gain radar channel but preferably lower than 1500 meters to guarantee a sufficient penetrating capability. The maximum range of the laser altimeter is $1500 \mathrm{~m}$, depending on surface and ambient conditions. Straight and level flight are preferred for gravity and magnetics and it is best if crossovers occur at similar elevations. During the past five austral seasons, with the highest priority of mapping 
the geometry and subice properties of ice sheets by airborne IPR in PEL, the Snow Eagle 601 flew at a height of $\sim 600 \mathrm{~m}$ over surface most of the time, usually requiring consistent flight elevation changes to match changes in surface elevation. However, the flight height decreased to $\sim 60 \mathrm{~m}$ when the signal attenuation in the ice was known to be high and penetrating capability was especially needed over areas with complex ice properties or deep subglacial valleys where the subglacial bedrock was difficult to detect because the IPR signals could be significantly attenuated or reflected away.

\subsection{Data Acquisition}

Except for the GT-2A gravimeter and JAVAD GNSS, the other airborne instruments are synchronously integrated by the Environment for Linked Streams Acquisition (ELSA) system [18], which was developed by UTIG. All integrated instruments can be controlled and monitored and their data are received and recorded by ELSA. ELSA also allows operators to manage data collection and check data quality in real-time on all flights. The system integration relies on an accurate time stamps $(10 \mu s)$ calibrated with real-time GPS data. Data streams from different instruments with different sampling rates are received by ELSA along with the time and then written into two data files with one for radar data and the other for data from the other instruments [18]. The data files are recorded to a solid-state disk by ELSA. The gravity data are acquired and recorded separately into a USB flash disk by GT-2A's central data unit.

Flight notes are filled out, noting the times of engine start, taxi, takeoff and other major events. An instrument checklist is filled out every $30 \mathrm{~min}$ by FOP members and known or suspected aircraft or instrument anomalies are documented carefully. A base magnetometer and two GPS base stations are operated during each flight; at the end of each airborne survey, all media and flight notes are secured in weatherproof cases and delivered to BOP for data processing.

\subsection{Data Processing}

Raw data from a survey flight will be preliminarily processed by BOP before the next flight. The objectives of field data processing are to generate readable datasets of all instruments with corresponding PSTs, link all measurements to GPS positions, check the quality of the collected data, ensure all instruments functioned as designed and that data quality was sufficient to address the questions motivating the flight plan. The data processing system is set up at either the skiway camp or at Zhongshan Station and consists of two laptops for data processing, one or two QNAP (QNAP Systems, Inc.) RAIDs (redundant array of independent disks) for data storage and accessing, a printer and a tape driver for data archiving as well as a router and switch used to connect all the devices to a local network (Figure 3). Field data processing starts with downloading raw data from all media to an "orig" folder created in QNAP. Raw data are then converted into readable binary and ASCII files and separated by different instrument streams and different PSTs through a data breakout step (Figure 4). During the breakout step, each data stream from individual instruments is processed through custom code packages to improve the data quality and meet the demands of the data plotting and QC. For example, the IPR data are processed through down conversion, the removal of direct current offsets, pulse compression, coherent stacking and incoherent stacking. All measurements are linked with accurate time stamps, which can be traced to the GPS times and position with high accuracy. Data after the breakout step are saved in a "targ" folder. Finally, data from all instruments are plotted with the time and distance for each PST onto QC sheets to conveniently evaluate all data streams. 


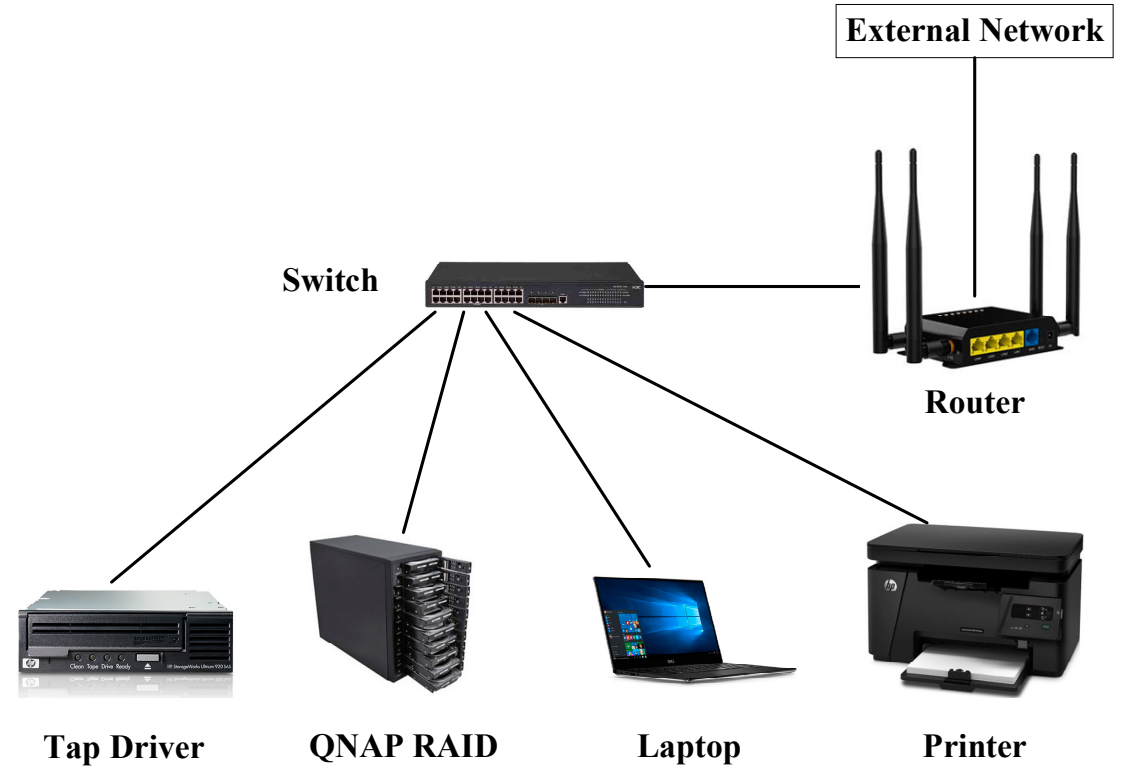

Figure 3. Field data processing, quality control and archiving system.

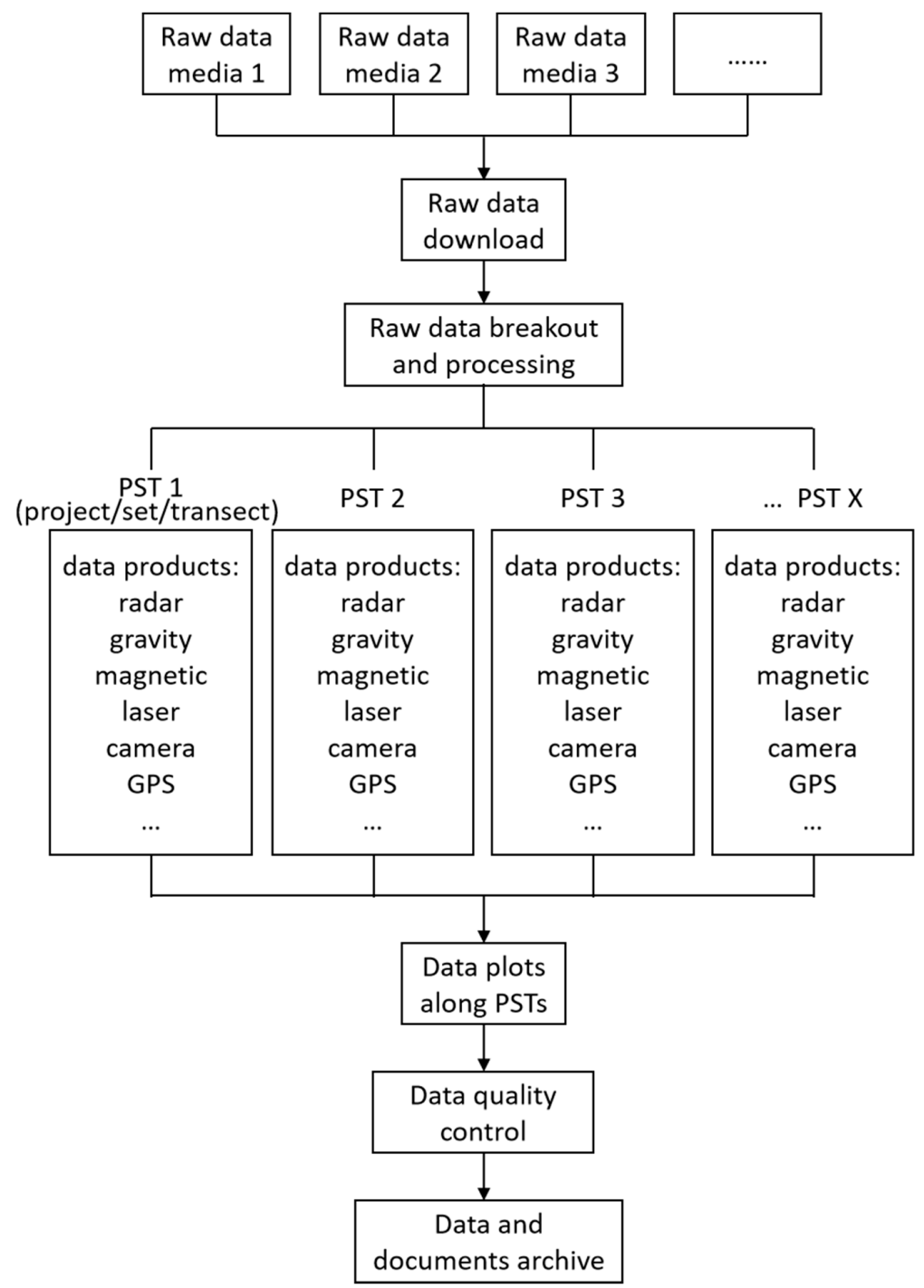

Figure 4. Flow chart of field data processing and quality control. 


\subsection{Data Quality Control}

Data quality is checked after each flight by evaluating whether each device produced the expected data quality and, in parallel, whether the resulting data quality is sufficient to make the required interpretations of ice and subglacial geological conditions required by the motivating science questions behind the flight [18]. Device QC is checked with the data streams from four aircraft GNSS antennas, an Inertial Measurement Unit (IMU) and GNSS and magnetic base stations. Ice QC is checked with data streams from both the IPR high and low gain channels, the airborne GPS antenna at the aircraft CG and the IMU and laser altimeter are jointly analyzed. Geology QC is checked with data streams from the airborne gravimeter, magnetometer, IPR high gain channel and the airborne GNSS antenna at the CG. QC evaluations are made by BOP members based on a uniform data quality scale in four levels: good, moderate, poor and very poor (including data gaps). Joint interpretations by BOP and FOP members are made with particular emphasis on potential device problems that must be solved before another flight is possible or indications that lines must be re-flown due to poor flight conditions (e.g., excessive turbulence, clouds blocking laser data). QC records are printed in black and white and evaluations are hand-colored in four associated colors: blue $=$ good, yellow $=$ moderate, orange $=$ poor, pink = very poor). A review sheet associated with the printed record is used for detailed notes during the review process.

\subsection{Data and Documents Archive}

All data uploaded to the "orig" and "targ" repositories including notes produced in flight and during the QC process are archived on magnetic storage tapes using a tape drive following the QC process. Four tapes are written after each flight including two redundant copies of each of the raw IPR and serial data (including all documents such as flight plans, flight notes, checklists and QC sheets). At the end of the season, the QNAP RAID and each set of tapes are shipped to PRIC using different means for added robustness against cargo delays, lost luggage or other problems [18].

\section{Progress and Prospects}

\subsection{Progress}

Scientific investigation is one of the most important tasks for Snow Eagle 601 aviation operations in Antarctica. However, the aircraft must also be available for emergency response and assisting with transportation logistics between Antarctic stations. In the past five austral seasons, Snow Eagle 601 has averaged about 120 flight hours for scientific survey out of a total of about 320 flight hours allocated for each season. Approximately $130 \mathrm{~h}$ are used to move the aircraft in and out of Antarctica from Calgary, Canada. Among the $\sim 120 \mathrm{~h}$ of scientific flights each season, about $40 \mathrm{~h}$ are reserved for international collaborations. To date, China has collaborated with Australia, France, Russia, South Korea and the USA for scientific or logistical duties, sharing critical aviation capabilities in Antarctica. International collaborations improve the usability and coverage of Snow Eagle 601 in Antarctica and also benefit airborne data interpretation and scientific research. In China, scientists from many universities and institutions including Tongji University, Beijing University of Technology, Wuhan University, Beijing Normal University, Zhejiang University and the First Institute of Oceanography of the Ministry of Natural Resources (MNR) have been involved in airborne surveys in the field or through post-season data processing, interpretation and scientific research. Radioglaciological and aerogeophysical studies of Antarctica in China are significantly extended and improved through the scientific operations of Snow Eagle 601.

In its first five austral seasons, Snow Eagle 601 has acquired data along more than 175,000 line kilometers. The flight lines cover many critical areas in East Antarctica including Princess Elizabeth Land, Grove Mountains, the Amery Ice Shelf, the South Prince Charles Mountains, Ridge B, the West Ice Shelf, the Shackleton Ice Shelf, the Titan Dome, the George V Coast and the David Glacier Catchment, as shown in Figure 5. 


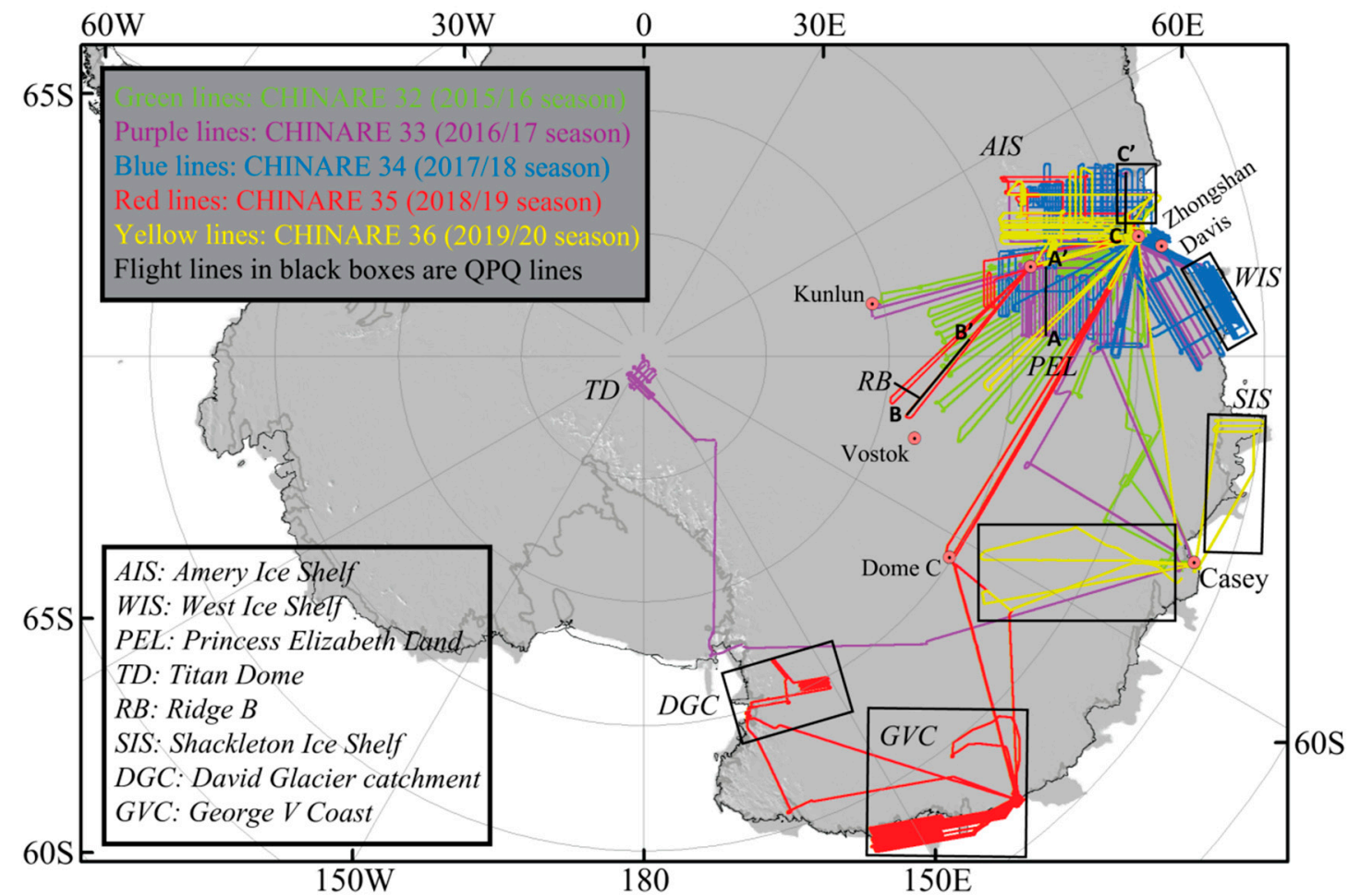

Figure 5. Flight line coverage of airborne surveys in the past five austral seasons by Snow Eagle 601.

Profiles along A-A', B-B' and C-C' are shown in Figure 6.

The initial scientific motivations for the scientific operations of Snow Eagle 601 were to map the ice sheet geometry, bedrock topography and infer the subglacial conditions and geological conditions of PEL, the largest data gap in Antarctica prior to these efforts. The Bedmap 2 [15], ADMAP 2 [16] and AntGG [17] datasets reflected the state of coverage from ice bottom elevation, magnetics and gravity field mapping before the beginning of Snow Eagle 601 operations, highlighting the large data gap in PEL. Moreover, ice surface features in the satellite data potentially showed a large subglacial lake in PEL and an extensive canyon system beneath the ice that may link the lake with the grounding zone of the West Ice Shelf [19]. However, these have not yet been identified and characterized by geophysical observations and their impacts on the dynamics and stability of the interior ice sheet have not been well studied, leading to our poor understanding of future mass balance in this sector and its potential contribution to the sea level. Data collected by Snow Eagle 601 over the last five years in PEL have filled this gap and ice thickness and bed topography datasets have been released by Cui et al. [20]. Airborne radar data along a transect (LSE/GCX0e/Y87a) also validate the existence of the subglacial lake (a relatively light and flat reflector in Figure 6a). Airborne survey data will continue to provide key parameters and boundary conditions for numerical models to study past and future ice sheet dynamics in PEL. 

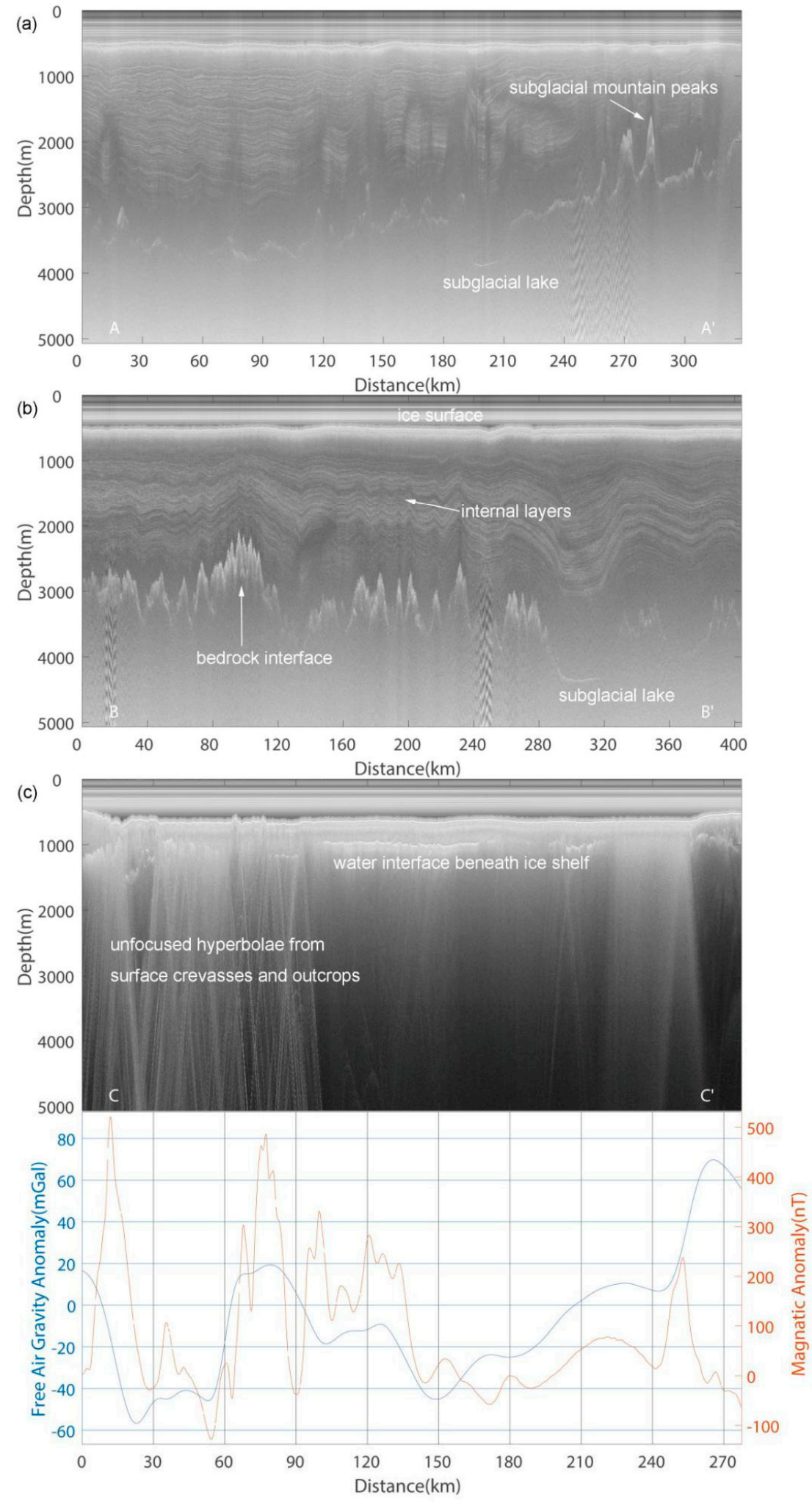

Figure 6. Data profiles along project/set/transects (PSTs) in Princess Elizabeth Land (PEL), Ridge B and the Amery Ice Shelf, respectively. (a) Radargram along LSE/GCX0e/Y87a, LSE = Lake of Snow Eagle; (b) radargram along TSH/GCX0g/R41a; (c) radargram, free air gravity anomaly and magnetic anomaly along AMY/GCX0e/Y184a, AMY = Amery. 
Further airborne surveys have been extended to investigate the Amery Ice Shelf, the West Ice Shelf and the Shackleton Ice Shelf with the motivation of inferring bathymetry using gravity data [12], identifying properties of basal ice and grounding lines or zones and mapping ice shelf geometry with a more modern radar system relative to previous data. Along a transect near the ice front of the Amery Ice Shelf, airborne radar data have revealed a clear water interface beneath the ice shelf and unfocused hyperbolae caused by outcroppings and surface crevasses in the coastal region (Figure 6c). Gravity and magnetic anomalies along the transect show obvious relationships, which is a joint result from the deep geological structure and lithosphere (Figure 6c). Ice shelves are the most vulnerable components of ice sheets due to their direct contact with warm ocean water and play a vital role in the stability of interior ice sheets [21]. Studies show that ice shelves over most of the West Antarctic Ice Sheet (WAIS) are experiencing rapid dynamic thinning and grounding line retreat [22,23]. Ice shelves in the East Antarctic Ice Sheet (EAIS) are also beginning to earn increased attention to recently observed changes; for example, recent studies of the Totten Glacier Ice Shelf revealed rapid changes and ocean conditions similar to what was found in the coastal WAIS $[12,24,25]$ indicating the possible instability of sectors of the EAIS. However, most ice shelves in the EAIS have not been adequately surveyed. Airborne surveys in these regions are ongoing by both the ICECAP/EAGLE (East Antarctic Grounding Lines Experiments) and ICECAP/PEL campaigns through international collaborations in Australia, China, France, Italy, South Korea, the UK and the USA. These programs have particularly emphasized coastal areas, such as the George V Coast, which is under-surveyed but is critically important for understanding the fate of the interior Wilkes Subglacial Basin.

In the austral season of 2018/19, the first effort was made to survey Ridge B. Ridge B is located in the deep interior of the EAIS. Modeling results indicated that Ridge B is one of the most likely places to host the oldest ice on Earth [26] and, therefore, the longest high resolution climate record but there are no sufficient observations there to support and verify this. Two critical flights were successfully achieved using a temporary skiway located at the Chinese Taishan Station as a transit and refueling stop. Due to the location of the interior of Antarctica, the radargram along the PST of TSH/GCX0g/R41a in Ridge B showed remarkable internal layers and continuous, clear, frequently varied bedrock topography (Figure $6 \mathrm{~b}$ ). These are essential for extracting ice thickness, bedrock elevation, past snow accumulation rate and basal conditions and have a significant value for estimating the bottom ice age in this region. The airborne data in Ridge B can improve our understanding of ice sheet geometry and improve the modeling accuracy of ice age estimation. In addition, two short surveys with similar research motivations were completed over the Titan Dome, another "old ice" target, by Snow Eagle 601 during the 2015/2016 and 2016/2017 austral seasons when the aircraft was ferrying out of Antarctica [27].

Aerogeophysical surveys in the Grove Mountains and the South Prince Charles Mountains have mainly focused on geological studies. Measurements in the regions offer a valuable extension for geological studies based on outcrops [28] and could have significant implications for the assembly and breakup of the Gondwana Supercontinent [16].

\subsection{Future Work}

In the past five austral seasons, Snow Eagle 601 has successfully surveyed PEL, the Amery Ice Shelf and the West Ice Shelf with moderately high spatial resolution. Data processing and publication should be accelerated to reveal the ice thickness, bedrock topography, internal layers and basal conditions of the ice sheets and ice shelves as well as analyzing the gravimetric and magnetic anomalies of the continent to an acceptable data density and accuracy. These results will significantly improve our knowledge of the ice sheet and its changes and of the geological settings of the regions. Flight lines over the South Prince Charles Mountains, Ridge B and other interior areas are still sparse. More attention should be given to these areas in future years. It is difficult to survey these areas from a coastal skiway because they require a very long transit; therefore, inland skiways such as Taishan Station, Kunlun Station, Vostok Station and South Pole Station should be considered through international 
collaborations and partnerships. International collaborations should also be strengthened to survey fast changing areas around the continent such as grounding zones, coastal outlet glaciers and ice shelves in the Ross Sea and Amundsen Sea sectors with powerful IPRs and aerogeophysical instruments to better characterize and infer the ice geometry, bedrock topography, basal conditions and bathymetry. Complex surface conditions and the strong attenuation of radar signals in these small-scale areas are a substantial challenge for airborne surveys. Moreover, to survey these areas, nearby landing areas are also needed. The continent-ocean transition zones in the sector of the Southern Indian Ocean are another target for the scientific operations of Snow Eagle 601 in future years. Surveys there can help to build knowledge on the connection of the geological structure between the continent and ocean there, which has significant implications for the joint interpretation of the geological evolution of Antarctica and the surrounding continents.

Updated and improved airborne instruments are also needed in the near future. The existing instruments have a strong capability for aerogeophysical investigation but are insufficient to map snow and shallow ice layers and are not sufficient to capture ice surface properties and their changes with high efficiency. Airborne shallow ice and snow radars are needed to map snow and shallow ice stratigraphy in detail, which is important to study the mass balance of Antarctica. The airborne laser altimeter and camera are not sufficient to measure surface elevation efficiently and characterize surface features in good quality. An advanced airborne optical camera or photogrammetry system as well as airborne LiDAR (light detection and ranging) and SAR (synthetic aperture radar) systems are priority choices for updating the Snow Eagle 601 airborne platform.

Snow Eagle 601 will continue operating in Antarctica for the foreseeable future. Airborne surveys remain an important part of the annual tasking; however, flight hours dedicated to scientific operations may be reduced with increased logistical requirements. Hopefully, more than 100 flight hours ( 30,000 km flight lines) can be achieved in the upcoming seasons. In addition to the continuous and long-term data acquisition by Snow Eagle 601 in Antarctica, both national and international collaborations for data interpretation and research should be strengthened to extend the influence of Snow Eagle 601 scientific operations and promote scientific achievements.

\section{Conclusions}

In 2015, for the first time, China deployed its fixed-wing aircraft in Antarctica, which has led to substantial scientific and logistical achievements. An airborne IPR, a gravimeter, a magnetometer, a laser altimeter and a camera were simultaneously configured and integrated onto the aircraft at the same time. The airborne scientific platform has been applied to investigate many critical areas in East Antarctica in the past five austral seasons. Until now, over 175,000 line $\mathrm{km}$ of data have been surveyed in East Antarctica, not only filling the largest remaining data gap but also covering surrounding areas such as the Amery Ice Shelf, the West Ice shelf, Ridge B and the Titan Dome. Successful scientific operations of Snow Eagle 601 in the past five years prove the reliability and capability of the airborne platform and aviation support for airborne surveys in Antarctica.

Nationally, extensive collaboration with universities and institutes should be strengthened and deepened to carry out data interpretation and scientific research. Internationally, we have established close collaborations with the University of Texas at Austin, Imperial College London, the Australian Antarctic Division, the French Polar Institute Paul-Émile Victor and the Korea Polar Research Institute under the ICECAP framework. In the coming years, we will continue to survey the interior of the Antarctic Ice Sheet where flight lines are still sparse and launch new campaigns to survey the Ross and Amundsen Sea sectors as well as the transition zones between the continent and ocean. The resulting data will continue to contribute to international compilation efforts including the Bedmap, ADMAP and AntGG databases while improving our understanding of the ice sheet and subglacial geology of the Antarctic continent. 
Author Contributions: Writing original draft, X.C.; X.Z. and S.L.; methodology and software, J.S.G.; S.L. and X.C.; investigation, J.S.G.; X.C.; J.G. and L.L.; supervision, B.S.; review and editing, all authors. All authors have read and agreed to the published version of the manuscript.

Funding: This work was supported by the National Natural Science Foundation of China (41941006, 41730102, 41776186), the National Key R\&D Program of China (2019YFC1509102, 2018YFB1307504), the G. Unger Vetlesen Foundation, NSF grants PLR-1543452 and PLR-1443690, the Department for Business Innovation and Skills, the British Council and the US State Department.

Acknowledgments: We thank the Chinese Antarctic expedition teams and Kenn Borek Air Ltd. aircraft crew for their support of aviation operations as well as Laura Lindzey, Gregory Ng, Feras Habbal, Wei and other ICECAP/PEL members for their contributions to scientific operations of Snow Eagle 601. We also thank the reviewers for their constructive and helpful comments and suggestions for improving the quality of our manuscript. This is UTIG contribution \#3690.

Conflicts of Interest: The authors declare no conflict of interest.

\section{References}

1. Andrew, S.; Amanda, F.H.; Louise, F.S. Trends and connections across the Antarctic cryosphere. Nature 2018, 558, 223-232.

2. Kennicutt, M.C.; Chown, S.L.; Cassano, J.J.; Liggett, D.; Massom, R.A.; Peck, L.S.; Rintoul, S.R.; Storey, J.W.V.; Vaughan, D.G.; Wilson, T.J.; et al. Polar research: Six priorities for Antarctic science. Nature 2014, 512, $23-25$. [CrossRef]

3. Kennicutt 1l, M.C.; Bromwich, D.; Liggett, D.; Njastad, B.; Peck, L.S.; Rintoul, S.R.; Ritz, C.; Siegert, M.J.; Aitken, A.R.A.; Brooks, C.M.; et al. Sustained Antarctic Research: A 21st Century Imperative. One Earth 2019, 1, 95-113. [CrossRef]

4. Evans, S. Radio techniques for the measurement of ice thickness. Polar Record. 2019, 11, 406-410. [CrossRef]

5. Cui, X.; Sun, B.; Zhang, X.; Zhang, D.; Li, X.; Tang, X.; Tian, G. A review of ice radar's technical development in polar ice sheet investigation. Chin. J. Polar Res. 2009, 21, 322-335.

6. Mirko, S.; Graeme, E.; Kirsty, T. Airborne platforms help answer questions in polar geosciences. Eos $2017,98$. [CrossRef]

7. Schroeder, D.M.; Dowdeswell, J.A.; Siegert, M.J.; Bingham, R.; Chu, W.; Mackie, E.J.; Siegfried, M.R.; Vega, K.I.; Emmons, J.R.; Winstein, K. Multidecadal observations of the Antarctic ice sheet from restored analog radar records. Proc. Natl. Acad. Sci. USA 2019, 116, 18867-18873. [CrossRef] [PubMed]

8. Bell, R.E.; Ferraccioli, F.; Creyts, T.T.; Braaten, D.; Corr, H.F.; Das, I.; Damaske, D.; Frearson, N.; Jordan, T.; Rose, K.; et al. Widespread Persistent Thickening of the East Antarctic Ice Sheet by Freezing from the Base. Science 2011, 331, 1592-1595. [CrossRef] [PubMed]

9. Jeofry, H.; Ross, N.; Corr, H.F.J.; Li, J.; Morlighem, M.; Gogineni, P.; Siegert, M.J. A new bed elevation model for the Weddell Sea sector of the West Antarctic Ice Sheet. Earth Syst. Sci. Data 2018, 10, 711-725. [CrossRef]

10. Jordan, T.A.; Martin, C.; Ferraccioli, F.; Matsuoka, K.; Corr, H.F.; Forsberg, R.; Olesen, A.; Siegert, M. Anomalously high geothermal flux near the South Pole. Sci. Rep. 2018, 8, 1-8. [CrossRef]

11. Young, D.A.; Wright, A.P.; Roberts, J.L.; Warner, R.C.; Young, N.W.; Greenbaum, J.S.; Schroeder, D.M.; Holt, J.W.; Sugden, D.E.; Blankenship, D.D.; et al. A dynamic early East Antarctic Ice Sheet suggested by ice-covered fjord landscapes. Nature 2011, 474, 72-75. [CrossRef] [PubMed]

12. Greenbaum, J.S.; Blankenship, D.D.; Young, D.A.; Richter, T.G.; Roberts, J.L.; Aitken, A.R.A.; Legresy, B.; Schroeder, D.M.; Warner, R.C.; van Ommen, T.D.; et al. Ocean access to a cavity beneath Totten Glacier in East Antarctica. Nat. Geosci. 2015, 8, 294-298. [CrossRef]

13. Cui, X.; Greenbaum, J.S.; Beem, L.H.; Guo, J.; Ng, G.; Li, L.; Blankenship, D.; Sun, B. The First Fixed-wing Aircraft For Chinese Antarctic Expeditions: Airframe, Modifications, Scientific Instrumentation and Applications. J. Environ. Eng. Geophys. 2018, 23, 1-13.

14. Karlsson, N.B.; Binder, T.; Eagles, G.; Helm, V.; Pattyn, F.; Van Liefferinge, B.; Eisen, O. Glaciological characteristics in the Dome Fuji region and new assessment for "Oldest Ice". Cryosphere 2018, 12, 2413-2424. [CrossRef]

15. Fretwell, P.T.; Pritchard, H.D.; Vaughan, D.G.; Bamber, J.L.; Barrand, N.E.; Bell, R.E.; Bianchi, C.; Bingham, R.G.; Blankenship, D.D.; Casassa, G.; et al. Bedmap2: Improved ice bed, surface and thickness datasets for Antarctica. Cryosphere 2012, 7, 375-393. [CrossRef] 
16. Golynsky, A.V.; Ferraccioli, F.; Hong, J.; Golynsky, D.A.; Von Frese, R.R.; Young, D.A.; Blankenship, D.D.; Holt, J.W.; Ivanov, S.V.; Kiselev, A.V.; et al. New Magnetic Anomaly Map of the Antarctic. Geophys. Res. Lett. 2018, 45, 6437-6449. [CrossRef]

17. Scheinert, M.; Ferraccioli, F.; Schwabe, J.; Bell, R.E.; Studinger, M.; Damaske, D.; Jokat, W.; Aleshkova, N.; Jordan, T.; Leitchenkov, G.; et al. New Antarctic gravity anomaly grid for enhanced geodetic and geophysical studies in Antarctica. Geophys. Res. Lett. 2016, 43, 600-610. [CrossRef]

18. Ng, G.; Lindzey, L.E.; Young, D.A.; Buhl, D.P.; Kempf, S.D.; Beem, L.H.; Roberts, J.L.; Greenbaum, J.S.; Blankenship, D.D. UTIG's Approach to Managing Polar Aerogeophysical Data in the Field: Philosophy and Examples from Fixed Wing and Helicopter Surveys; UTIG Technical Report; University of Texas, Institute for Geophysics: Austin, TX, USA, 2020.

19. Jamieson, S.S.R.; Ross, N.; Greenbaum, J.S.; Young, D.A.; Aitken, A.R.A.; Roberts, J.L.; Blankenship, D.D.; Siegert, M.J. An extensive subglacial lake and canyon system in Princess Elizabeth Land, East Antarctica. Geology 2016, 44, 87-90. [CrossRef]

20. Cui, X.; Jeofry, H.; Greenbaum, J.S.; Guo, J.; Li, L.; Lindzey, L.E.; Habbal, F.A.; Wei, W.; Young, D.A.; Ross, N.; et al. Bed topography of Princess Elizabeth Land in East Antarctica. Earth Syst. Sci. Data Discuss. 2020. in review. [CrossRef]

21. Pritchard, H.D.; Ligtenberg, S.R.M.; Fricker, H.A.; Vaughan, D.G.; Van den Broeke, M.R.; Padman, L. Antarctic ice-sheet loss driven by basal melting of ice shelves. Nature 2012, 484, 502-505. [CrossRef]

22. Paolo, F.; Fricker, H.; Padman, L. Volume loss from Antarctic ice shelves is accelerating. Science 2015, 348, 327-331. [CrossRef] [PubMed]

23. Rignot, E.; Mouginot, J.; Morlighem, M.; Seroussi, H.; Scheuchl, B. Widespread, rapid grounding line retreat of Pine Island, Thwaites, Smith, and Kohler glaciers, West Antarctica, from 1992 to 2011. Geophys. Res. Lett. 2014, 41, 3502-3509. [CrossRef]

24. Li, X.; Rignot, E.; Morlighem, M.; Mouginot, J.; Scheuchl, B. Grounding line retreat of Totten Glacier, east Antarctica, 1996 to 2013. Geophys. Res. Lett. 2015, 42, 8049-8056. [CrossRef]

25. Rintoul, S.R.; Silvano, A.; Pena-Molino, B.; van Wijk, E.; Rosenberg, M.; Greenbaum, J.S.; Blankenship, D.D. Ocean heat drives rapid basal melt of the Totten ice shelf. Sci. Adv. 2016, 2, E1601610. [CrossRef] [PubMed]

26. Van Liefferinge, B.; Pattyn, F. Using ice-flow models to evaluate potential sites of million year-old ice in Antarctica. Clim. Past 2013, 9, 2335-2345. [CrossRef]

27. Beem, L.H.; Young, D.A.; Greenbaum, J.S.; Blankenship, D.D.; Guo, J.; Bo, S. Characterization of Titan Dome, East Antarctica, and potential as an ice core target. Cryosphere 2020, in review. [CrossRef]

28. Liu, X.; Zhao, Y. Geological surveys in East Antarctica by Chinese expeditions over the last 20 years: Progress and prospects. Chin. J. Polar Res. 2018, 30, 268-286. 